\title{
Retraction: Physiological basis and image processing in functional magnetic resonance imaging: neuronal and motor activity in brain
}

\author{
Rakesh Sharma ${ }^{* *}$ and Avdhesh Sharma ${ }^{2}$
}

\author{
* Correspondence: rpk1@columbia. \\ edu \\ ${ }^{1}$ Departments of Medicine and \\ Radiology, Columbia University, \\ New York, NY 10032, USA \\ Full list of author information is \\ available at the end of the article
}

\section{Retraction}

This article [1] has been retracted by the publisher because of significant overlap with figures from previously published work [2,3] without appropriate attribution or permissions. We were unable to contact the authors of the article, despite our best efforts. We apologise to all affected parties for the inconvenience caused.

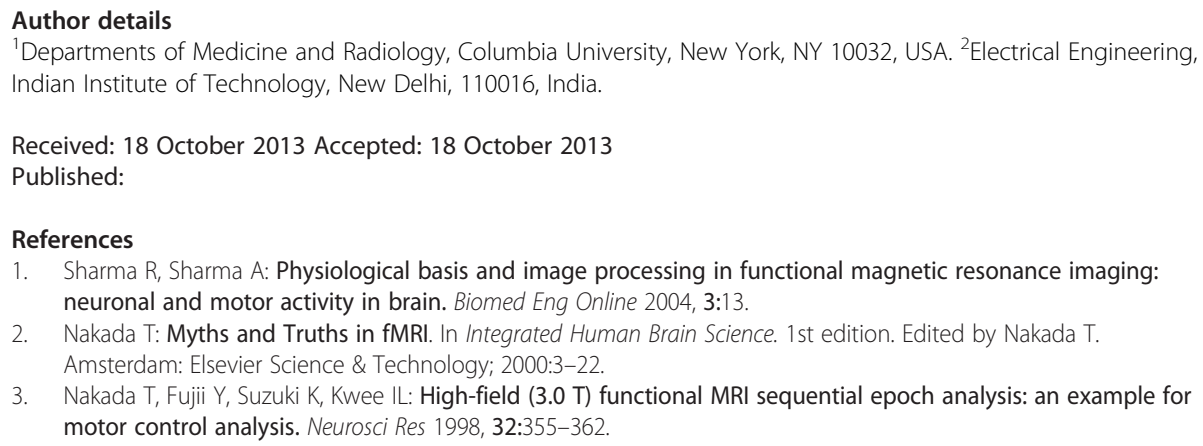

1. Sharma R, Sharma A: Physiological basis and image processing in functional magnetic resonance imaging: neuronal and motor activity in brain. Biomed Eng Online 2004, 3:13

2. Nakada T: Myths and Truths in fMRI. In Integrated Human Brain Science. 1st edition. Edited by Nakada T. Amsterdam: Elsevier Science \& Technology; 2000:3-22.

3. Nakada T, Fujii Y, Suzuki K, Kwee IL: High-field (3.0 T) functional MRI sequential epoch analysis: an example for motor control analysis. Neurosci Res 1998, 32:355-362.

doi:10.1186/1475-925X-12-113

Cite this article as: Sharma and Sharma: Retraction: Physiological basis and image processing in functional magnetic resonance imaging: neuronal and motor activity in brain. BioMedical Engineering OnLine 2013 12:113.

\section{Biomed Central}

(c) 2013 Sharma and Sharma; licensee BioMed Central Ltd. This is an Open Access article distributed under the terms of the Creative Commons Attribution License (http://creativecommons.org/licenses/by/2.0), which permits unrestricted use, distribution, and reproduction in any medium, provided the original work is properly cited. The Creative Commons Public Domain Dedication waiver (http://creativecommons.org/publicdomain/zero/1.0/) applies to the data made available in this article, unless otherwise stated. 